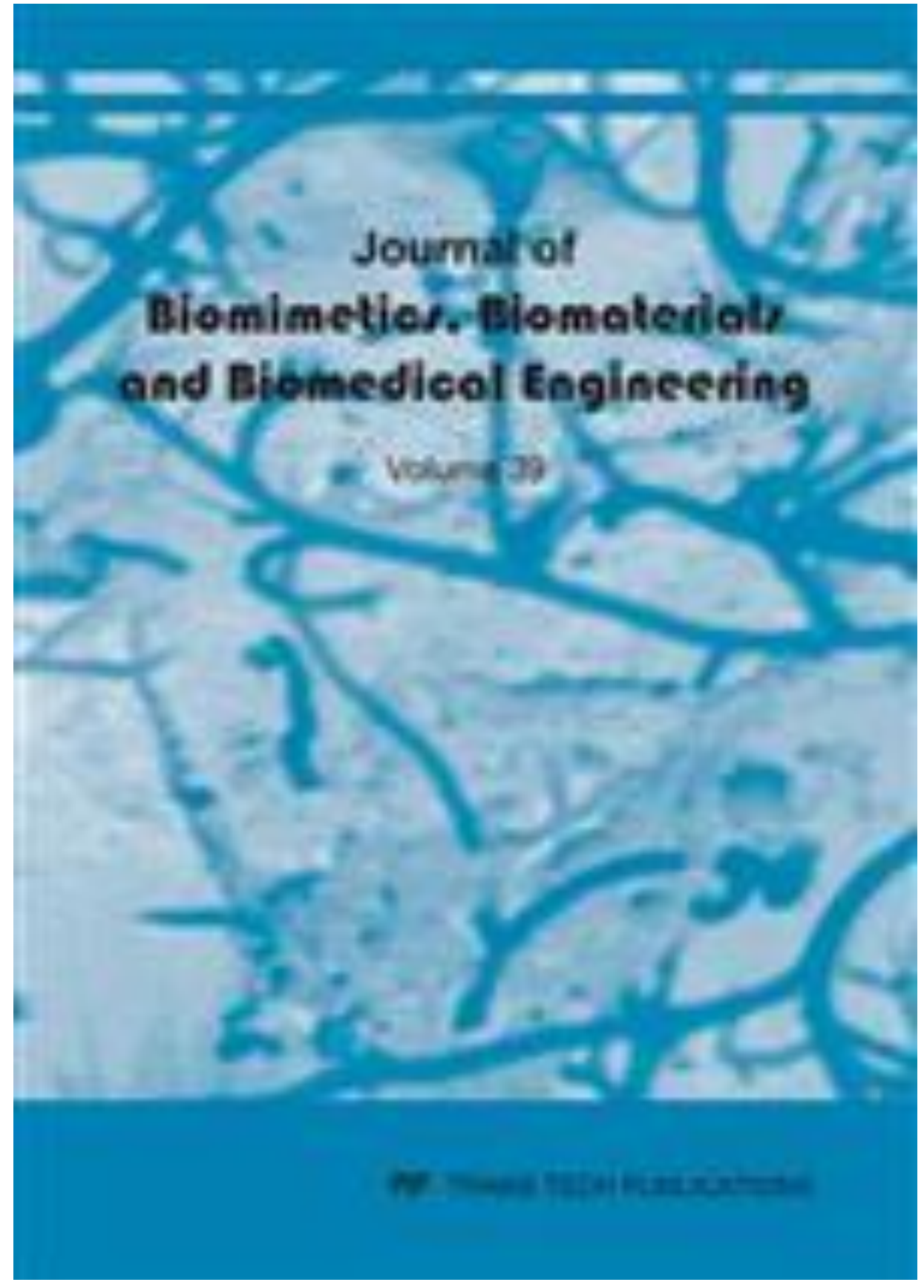




\section{Periodicals}

\section{Journal of Biomimetics, Biomaterials and Biomedical Engineering ISSN: 2296-9845}

Volumes (/JBBBE)

My eBooks (/JBBBE/ebooks)

Details (/JBBBE/Details)

Editorial Board (/JBBBE/Editors)

Editor(s) in Chief

\section{Dr. Sooraj Hussain Nandyala}

ORCID (https://orcid.org/0000-0002-2736-5224).

Universidade do Porto, Departamento de Física, Faculdade de Ciências; Rua do Campo Alegre 687, Porto, 4169-007, Portugal;

Senior Editors

\section{Dr. Stanislav Kolisnychenko}

\section{Editorial Board}

\section{Mr. Souvik Das}

SHEIKHPARA A. R. M. POLYTECHNIC, GOVT. OF WEST BENGAL, MEDICAL LABORATORY TECHNOLOGY; Sheikhpara, Murshidabad, Nadia, India, 741235;

\section{Prof. Qing Ling Feng}

Tsinghua University, School of Materials Science and Engineering; Beijing, China, 100084;

\section{Dr. Yao Dong Gu}

Ningbo University; No.818, Fenghua Road, Ningbo, China, 315211;

\section{Prof. Mohammad Abu Jafar Mazumder}

King Fahd University of Petroleum and Minerals, Chemistry Department; P. O. Box \# 1683, Dhahran, Saudi Arabia, 31261;

\section{Dr. Krishna Madhavan}

University of Colorado at Denver, Health Sciences Center; Denver, USA; 


\section{Prof. F.N. Oktar}

Marmara University, Department of Bioengineering, Faculty of Engineering; Goztepe Campus, Engineering D Building, Kuyubasi, 34722, Turkey;

\section{Prof. Murugan Ramalingam}

Centre for Stem Cell Research (a Unit of inStem, Bengaluru), Christian Medical College and Hospital Campus; Bagayam, India, 632002;

\section{Prof. Débora dos Santos Tavares}

Federal University of Sergipe, Health Campus, Education in Health Department, Colégio Estadual Prof. Abelardo Romero Dantas; Rua Padre Alvares Pitangueira, n. 248., Centro Lagarto - SE, Brazil, 49.400-000;

\section{GET ACCESS (/ACCOUNT/SUBSCRIPTIONS)}

SYSTEM GUIDE (/INFO)

DISTRIBUTORS (/DISTRIBUTOR)

SUPPLEMENTS (/SUPPLEMENTS)

ABOUT US (/HOME/ABOUTUS)

POLICY \& ETHICS (/HOME/MISCONDUCT)

CONTACT US (/HOME/CONTACTS)

IMPRINT \& PRIVACY POLICY (/HOME/IMPRINTANDPRIVACYPOLICY)

SITEMAP (/HOME/SITEMAP) 


\section{Main Themes}

\section{Journal of Biomimetics, Biomaterials and Biomedical Engineering Vol. 39}

Volume 39

doi: https://doi.org/10.4028/www.scientific.net/JBBBE.39

(https://doi.org/10.4028/www.scientific.net/JBBBE.39)

Papers (/JBBBE.39)

Book (JJBBBE.39/book)

\section{Search}

Effects of Different Hardness in Bionic Soles on Lower Limb

Biomechanics (JJBBBE.39.1)

Authors: Ying Yue Zhang, Si Qin Shen, Julien S. Baker, Yao Dong Gu

Abstract: The design of modern footwear seems to have an excessive protective

effect on the function of the foot. The purpose of this study was to examine how

...more

Numerical Modeling of Blood Flow in a Healthy Aorta and Aorta with

Stent (IJBBBE.39.13).

Authors: Abdel Hakem Belaghit, Benaoumeur Aour, Mekki Larabi, Salah

Mebarki

Abstract: The treatment of aortic aneurysm varies according to each patient. Stent implantation is one of many methods used to stabilize diseases. The information

...more

Determination of the Optimum Material Gradient for a Functionally. 
Abstract: The treatment process of a tooth every short period has many

disadvantages to the dental patient, for instance, wasting time, losing money, and ...more

Employing Image Processing Techniques and Artificial Intelligence for

Automated Eye Diagnosis Using Digital Eye Fundus Images

(IJBBBE.39.40)

Authors: Ali Mohammad Alqudah, Hiam Alquraan, Isam Abu-Qasmieh, Alaa AlBadarneh

Abstract: Blindness usually comes from two main causes, glaucoma and diabetes. Robust mass screening is performed for diagnosing, such as screening that

...more

Simulator of Foetal Phonocardiographic Recordings and Foetal Heart

Rate Calculator (JJBBBE.39.57)

Authors: Anthony Joseph, Radek Martinek, Radana Kahankova, Rene Jaros, Jan Nedoma, Marcel Fajkus

Abstract: Nowadays, the classic diagnostic method to monitor general foetus wellbeing using the foetal heart rate conditions, ultrasonic cardiotography, is called ...more

The Impact of Hybrid Nano-Materials in Tooth Tissue Restoration

(IJBBBE.39.65).

Authors: Camtu Suhonen

Abstract: Tooth loss due to dental diseases, caries, and other related pathological conditions has plagued people and is the most prevalent cause of human organ

...more

Synthesis of N,N-Diethyl, N-Methyl Chitosan Chloride with Certain

Quaternization Degree and Molecular Spectroscopic and Thermo-

Morphological Study of the Alkylation (IJBBBE.39.77)

Authors: Shamo Z. Tapdigov, Samira F. Safaraliieva, Patrick Theato, Nizami A.

Zeynalov, Dilgam B. Taghiyev, Maria G. Raucci, Mirvari X. Hasanova

Abstract: The quartenizeid chloride derivative of natural polyaminosaccharide chitosan was synthesized in two stages with acetate aldehyde and methyl iodide ...more

The Role of Adipose Derived Mesenchymal Stem Cells (MSCs) to

Control Autoimmune Disease (JJBBBE.39.89)

Authors: Sumorejo Purwati, Lita D. Rahmawati, Dalimunthe Awalia, Fedik A.

Rantam, Ugroseno Y. Bintoro

Abstract: There are 80 types of autoimmune diseases (ADs) with some of the same symptoms, but causes are still unclear. The major treatment of ADs is ...more

Effect of Platelet-Rich Plasma and Amniotic Membrane in Patients with Rotator Cuff Repair (IJBBBE.39.98).

Authors: Heri Suroto, Ameria Pribadi, Dwikora Novembri Utomo, Ferdiansyah Mahyudin, Lukas Widhiyanto

Abstract: Rotator cuff disorders are the most common source of shoulder We're Online!

problems, ranging from mild strain to massive tears. Platelet-rich plasma (PRPY), 


\title{
Effect of Platelet-Rich Plasma and Amniotic Membrane in Patients with Rotator Cuff Repair
}

\author{
Heri Suroto ${ }^{1, a, *}$, Ameria Pribadi ${ }^{1, b}$, Dwikora Novembri Utomo ${ }^{1, c}$, \\ Ferdiansyah Mahyudin $^{1, \mathrm{~d}}$, Lukas Widhiyanto ${ }^{1, \mathrm{e}}$ \\ ${ }^{1}$ Department of Orthopedic and Traumatology, Faculty of Medicine, Universitas Airlangga/Dr. \\ Soetomo General Hospital, Indonesia
}

aheri-suroto@fk.unair.ac.id, bameria_pribadi@yahoo.com, dwikora-novembri-u@fk.unair.ac.id, dferdiansyah@fk.unair.ac.id, ${ }^{\mathrm{e}}$ lukas-w@fk.unair.ac.id

${ }^{*}$ Corresponding author: heri-suroto@fk.unair.ac.id

Keywords: platelet-rich plasma, amnion, rotator cuff repair, acromioplasty

\begin{abstract}
Rotator cuff disorders are the most common source of shoulder problems, ranging from mild strain to massive tears. Platelet-rich plasma (PRP), an autologous blood with platelets concentration above baseline values represents a source of multiple growth factors that promotes tissue repair. This review examines the potential of using PRP to augment rotator cuff repair. Reporting 4 patients with impingement syndrome and supraspinatus tear who underwent decompression acromioplasty and supraspinatus repair augmented with platelet-rich plasma and amniotic membrane. An evaluation was made 3-24 months postoperative using Shoulder Pain and Disability Index (SPADI). Average preoperative pain score is $64 \%$, disability score $54.58 \%$, and total score $58.19 \%$. Average postoperative pain score is $0 \%$, disability score $0.42 \%$, and total score $0.26 \%$ (Minimum Detectable Change at $90 \%$ confidence for pain score is $18 \%$, disability score $13 \%$, and total score 11\%). This result is consequent with research by Luoay Fallouh, stating that improvement is caused by growth factor effects in platelet-rich plasma which promotes soft tissue healing. It can be concluded that platelet-rich plasma and amniotic membrane have promising effects to enhance soft tissue healing in patients with rotator cuff syndrome. Shoulder function is restored with no limitation on daily activity and pain is no longer present.
\end{abstract}

\section{Introduction}

Approximately 4.5 million patient visits related to shoulder pain occur each year in the United States. Disorders of the rotator cuff range from painful rotator cuff syndromes to fullthickness tears of varying sizes and functional limitations. Outcomes for rotator cuff tears improve with both surgical and nonsurgical treatment [1].

The management of a rotator cuff tear is multifaceted. Choices of conservative management include resting the affected shoulder, analgesia and anti-inflammatory medications, physical therapy, activity modification, and subacromial injections of local anesthetic and/or steroid. Operative interventions include arthroscopic debridement of the tear or repair of the torn rotator cuff, with or without subacromial decompression [2].

Shoulder arthroscopy has been performed since 1970 and has helped to diagnose, repair, and accelerate healing time [3]. Development in shoulder arthroscopy is increasing every year along with the development of technology and new instruments. Proponents of this technique point to the lower risk of complications such as stiffness, infection, and deltoid avulsions. However, critics emphasize the lack of long-term outcome data, the controversy over the optimal fixation method, and the technical difficulty associated with this procedure [4].

Platelet-rich plasma was developed in the early 1970s as a fraction of plasma in which platelets are concentrated; thus, higher concentrations of the fundamental protein growth factors also exist in platelet-rich plasma. These growth factors are known to induce biological changes in the cell proliferation and matrix metabolism of a variety of connective tissues [5]. Platelet-rich plasma is defined as autologous blood with a concentration of platelets above baseline values. It is 
reported to represent a source of multiple growth factors that promote tissue repair [6]. This review examines the potential of using PRP to augment rotator cuff repair.

\section{Methods}

This is a case report descriptive study. The object of this study is 4 patients with impingement syndrome and rotator cuff tear (Figure 1) who underwent decompression acromioplasty and supraspinatus repair. Platelet-rich plasma and amniotic membrane (Figure 2) produced at Tissue Bank Dr. Soetomo General Hospital Surabaya were augmented during surgery (Figure 3). Patients were evaluated 3 months to 2 years postoperatively using Shoulder Pain and Disability Index (SPADI) questionnaire.

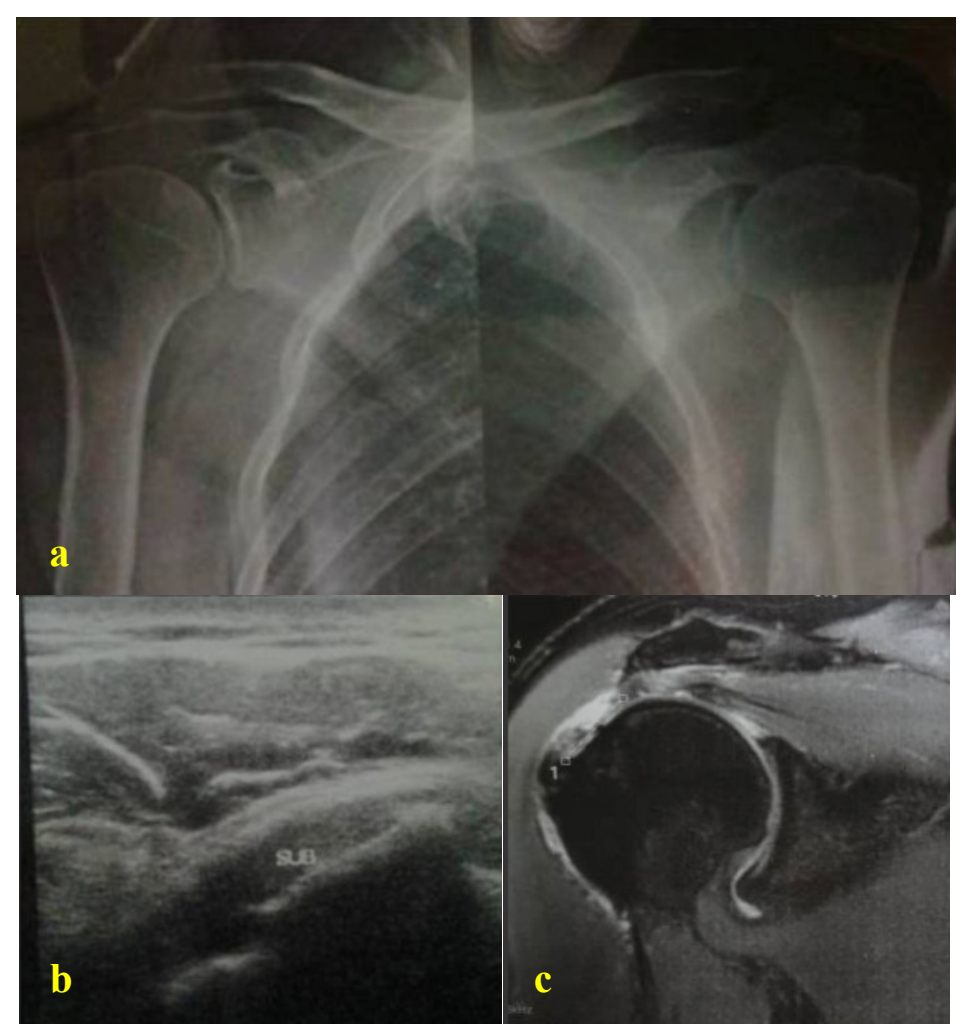

Figure 1. (a) X-ray shoulder D/S, (b) USG, (c) MRI

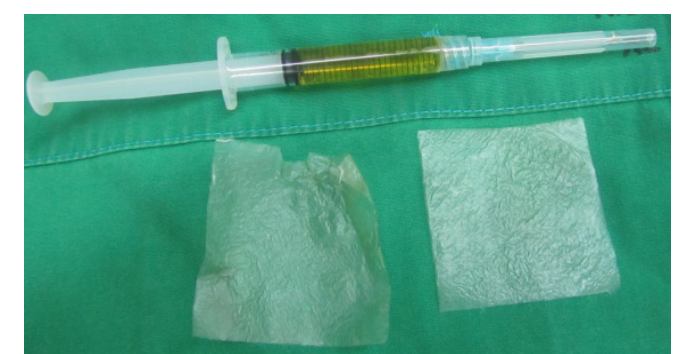

Figure 2. Platelet-rich plasma (yellowish liquid inside the spuit) and amniotic membrane (transparent sheet below the spuit) 

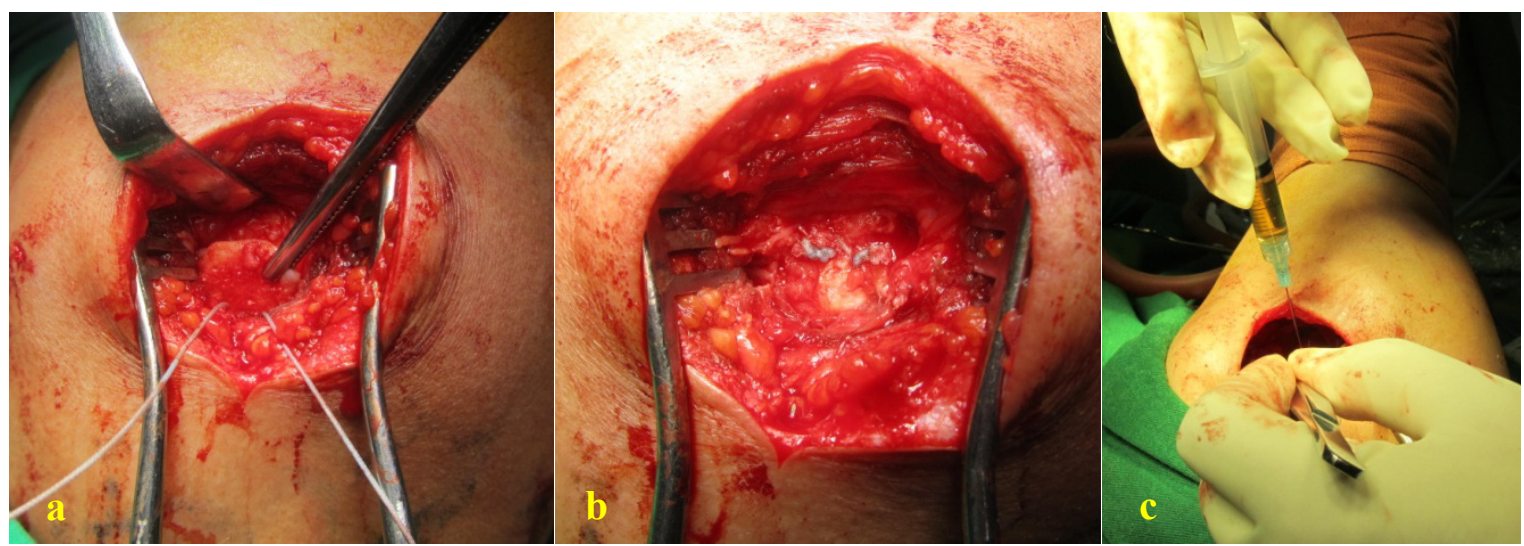

Figure 3. (a) Supraspinatus repair, (b) Amniotic membrane augmentation, (c) PRP augmentation

\section{Results and Discussion}

Average preoperative SPADI pain score is $64 \%$, disability score $54,58 \%$, and total score $58,19 \%$. Average postoperative SPADI pain score is $0 \%$, disability score $0,42 \%$, and total score $0,26 \%$ (Minimum Detectable Change at $90 \%$ confidence for pain score is $18 \%$, disability score $13 \%$, and total score 11\%) as shown in Figure 4.

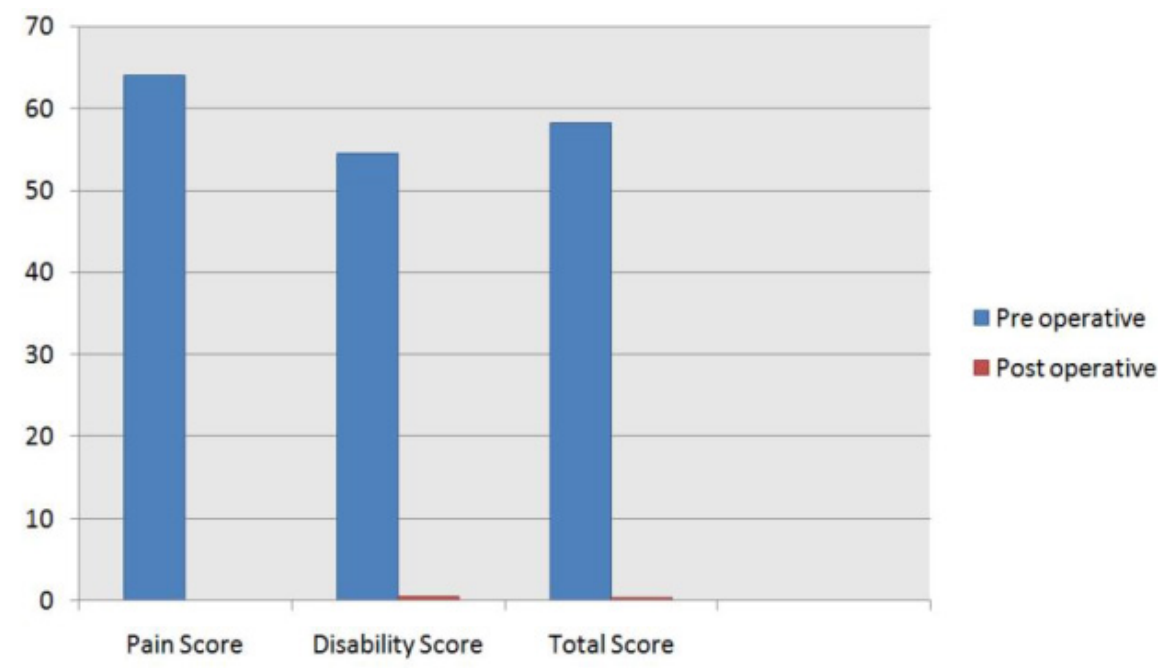

Figure 4. SPADI score pre and post surgery

Acceleration of muscle and tendon healing with PRP appears to be promising, but there is currently little clinical evidence to support its use. The efficacy of these PRP preparations is a controversial topic. Both clinical and animal studies, using variable preparation techniques have shown both success and failure. The fact that PRP is safe and prepared from autogenous blood may have allowed well-conducted clinical trials to proceed without optimizing the preparation of an ideal PRP in the laboratory first [6].

Research by Luoay Fallouh et al (2010) says that improvement after PRP augmentation is caused by high level of growth factor and total collagen production in platelet-rich plasma which promotes soft tissue healing [5].

A case report by Alderman (2012) demonstrates the effective use of PRP prolotherapy injections to stimulate repair of partial-thickness tears of rotator cuff tendons, with good results. Ultrasound guidance to ensure accurate placement is important when these specific deficits exist [7].

Hoppe et al (2013) recently showed that platelet-released growth factors heighten tenocyte proliferation and promote synthesis of the extracellular matrix to enhance healing of rotator cuff tendon in a laboratory culture medium [8]. 
A systematic review by Chahal et al (2012) showed that the use of PRP during rotator cuff repair did not have an effect on the overall retear rates or on several shoulder-specific outcome measures, including the Constant score, ASES score, UCLA shoulder score, SANE score, or SST score. However, there was a decrease in the rate of retear observed among patients treated with PRP in the setting of small- and medium-sized rotator cuff tears [9].

Randelli and colleagues (2011), Jo and colleagues (2011), and Castricini and colleagues (2011) all reported that PRP had no effect on tendon healing rates. Bergeson and colleagues (2012) compared repairs augmented with PRFM (Platelet-Rich Fibrin Matrix) to those without augmentation in tears at-risk for healing and found significantly worse healing in the PRFM group (44\%), compared with the non-PRFM group (62\%) after arthroscopic repair. Rodeo and colleagues (2012) recently reported similar findings of a negative effect of PRFM augmentation on cuff healing. Overall, these studies support that PRP or PRFM augmentation has a limited role in improving healing rates or outcomes after arthroscopic rotator cuff repair [10-14].

According to Gulotta (2009), some studies have shown that several factors are capable of increasing the strength of repairs in animal models. However, this appears to be accomplished through the production of more scar tissue, as opposed to the regeneration of native tissue. It is becoming clear that multiple factors may be needed to regenerate the native tendon-bone insertion site. The optimal timing and vehicle for growth factor deliver have remained elusive [15].

Given its excellent safety profile and ease of preparation, the use of PRP in sports medicine will likely continue to grow; however, clinical use should proceed cautiously because there is little, if any, high-level clinical evidence supporting the efficacy of this therapeutic modality [6].

\section{Conclusion}

In summary, PRP has emerged as a promising, but not proven, treatment option for tendon and muscle injuries and disorders. Basic science and animal investigation have begun to help in understanding the mechanism by which PRP affects tissue restoration. Because PRP is autologous and is prepared at the point of care, it also has an excellent safety profile. It may have the ability to transform the care of muscle and tendon injuries in both elite and recreational athletes. Welldesigned prospective randomized trials will be required to best understand how, when, and where to use PRP most effectively.

Most surgeons look at the risk-to-benefit ratio before making an operative or nonoperative decision. If the risk of a PRP injection does not pose significant poor consequences but may influence a positive outcome because of accelerated healing, many surgeons may choose to use PRP despite having data to justify its use or cost to the health care system.

\section{Acknowledgments}

The author would like to thank Tissue Bank Dr. Soetomo Hospital Surabaya for producing plateletrich plasma and amniotic membrane.

\section{References}

[1] Mather RC 3rd, Koenig L, Acevedo D, Dall TM, Gallo P, Romeo A et al. The Societal and Economic Value of Rotator Cuff Repair. J Bone Joint Surg Am. 2013; 95:1993-2000.

[2] Nicholas DC, Yuan XN, Juli MM. Management of degenerative rotator cuff tears: a review and treatment strategy. Sports Med Arthrosc Rehabil Ther Technol. 2012; 4:48.

[3] Lichtenberg Sven, Liem Dennis, et al. Influence of tendon healing after arthroscopic rotator cuff repair on clinical outcome using single-row Mason-Allen suture technique: a prospective, MRI controlled study. Knee Surg Sports Traumatol Arthrosc. 2006. Springer. 
[4] Ghodadra N, Provencher MT, Verma NN, Wilk KE, Romeo AA. Open, mini-open, and allarthroscopic rotator cuff repair surgery: indications and implications for rehabilitation. $\mathrm{J}$ Orthop Sports Phys Ther. 2009; 39(2):81-9.

[5] Fallouh L, Nakagawa K, Sasho T, Arai M, Kitahara S, Wada Y et al. Effects of Autologous Platelet-Rich Plasma on Cell Viability and Collagen Synthesis in Injured Human Anterior Cruciate Ligament. The Journal of Bone and Joint Surgery. 2010; 92:2909-16.

[6] Hall MP, Band PA, Meislin RJ, Jazrawi LM, Cardone DA. Platelet-rich Plasma: Current Concepts and Application in Sports Medicine. J Am Acad Orthop Surg. 2009; 17:602-8.

[7] Alderman Donna, Robbins Sean. Platelet Rich Plasma Prolotherapy for Rotator Cuff Tears. Practical Pain Management. 2012: 21-3.

[8] Hoppe S, Alini M, Benneker LM, Milz S, Boileau P, Zumstein MA. Tenocytes of chronic rotator cuff tendon tears can be stimulated by platelet-released growth factors. J Shoulder Elbow Surg. 2013; 22(3):340-9.

[9] Chahal J, Van Thiel GS, Mall N, Heard W, Bach BR, Cole BJ et al. The Role of Platelet-Rich Plasma in Arthroscopic Rotator Cuff Repair: A Systematic Review with Quantitative Synthesis. Arthroscopy. 2012; 28(11):1718-27.

[10] Randelli P, Arrigoni P, Ragone V, Aliprandi A, Cabitza P. Platelet-rich plasma in arthroscopic rotator cuff repair: a prospective RCT study, 2-year follow-up. J Shoulder Elbow Surg. 2011; 20:518-28.

[11] Jo CH, Kim JE, Yoon KS, Lee JH, Kang SB, Lee JH et al. Does platelet-rich plasma accelerate recovery after rotator cuff repair? A prospective cohort study. Am J Sports Med. 2011; 39(10):2082-90.

[12] Castricini R, Longo UG, De Benedeto M, Panfoli N, Pirani P, Zini R et al. Platelet-rich plasma augmentation for arthroscopic rotator cuff repair. A randomized controlled trial. Am $\mathrm{J}$ Sports Med. 2011; 39(2):258-65.

[13] Bergeson AG, Tashjian RZ, Greis PE, Crim J, Stoddard GJ, Burks RT. Effects of platelet-rich fibrin matrix on repair integrity of at-risk rotator cuff tears. Am J Sports Med. 2012; 40(2): 286-93.

[14] Rodeo SA, Delos D, Williams RJ, Adler RS, Pearle A, Warren RF. The effect of platelet-rich fibrin matrix on rotator cuff tendon healing: a prospective, randomized clinical study. Am $\mathrm{J}$ Sports Med. 2012; 40(6):1234-41.

[15] Gulotta Lawrence, Rodeo Scott. Growth Factors for Rotator Cuff Repair. Clin Sports Med. 2009; Vol 28: 13-23. 